DOI: $10.20287 /$ doc.d24.ac02

\title{
Miguel Mirra e seu método de trabalho de autogestão junto aos oprimidos no filme La cooperativa
}

\author{
Alessandro Constantino Gamo \& Luis Jorge Orcasitas Pacheco*
}

La cooperativa (Argentina, 2016, $75 \mathrm{~min}$.)

Direção e roteiro: Miguel Mirra

Produção: equipe de comunicação da União Solidária de Trabalhadores

(Unión Solidaria de Trabajadores, UST) e o Movimento de Documentaristas

Câmera: Maximiliano Rodríguez

Som: Patricio Medina

Textos: Florencia Galiotti

Música: banda Farolitos

Data de estréia:1 de dezembro de 2016

\section{Antecedentes do filme}

Antes de iniciar a própria análise do documentário La cooperativa, é importante ressaltar que os filmes de Miguel Mirra buscam mostrar a capacidade de resistência de movimentos sociais e culturais frente a diferentes formas de opressão. Trata-se de um posicionamento que retoma o que o cineasta Fernando Birri (1964: 13) assinalava como "as formas de afirmação dos valores positivos da sociedade: dos valores das pessoas. Suas reservas de força, seus empregos, suas alegrias, suas lutas, seus sonhos". ${ }^{1}$ Um aspecto que Pérez Esquivel (2017), conhecedor do trabalho documentário de Mirra, também enfatiza que:

Na filmagem das imagens, no pensamento, na elaboração dos conteúdos, Miguel Mirra não é um documentarista que filma certos fatos somente, ele também tenta aprofundar neles, para dar-lhes conteúdo e servir para a reflexão,

* Alessandro Constantino Gamo: Universidade Federal de São Carlos, Centro de Educação e Ciências Humanas, Programa de Pós-Graduação em Imagem e Som. 13565905, São Carlos, SP, Brasil. E-mail: alessgamo@yahoo.com

Luis Jorge Orcasitas Pacheco: Universidade Pontifícia Bolivariana, Escola de Ciências Sociais, Faculdade de Comunicação Social-Jornalismo. 050031, Medellín, Colômbia. E-mail: luis.orcasitas@gmail.com

1. [...] las formas de afirmación de los valores positivos de la sociedad: de los valores del pueblo. Sus reservas de fuerzas, sus trabajos, sus alegrías, sus luchas, sus sueños. Original em espanhol (Tradução dos autores). 
para a análise, para as vivências e, o que eu sempre digo, que essas memórias, não é para ficar no passado, essas memórias ajudam a iluminar o presente e este presente é o que dá sentido a esses documentários. ${ }^{2}$ (A. Pérez Esquivel, comunicação pessoal, 5 de julho de 2017)..

A partir da conjunção entre o cineasta e os atores sociais, surge um tipo de documentário "imperfeito" (como propõe Mirra) segundo Álvarez (2002: 466), que "permite que o diretor saque seu trabalho da realidade mais objetiva, diluindo todas as suas aspirações de 'diretor de cinema', na necessidade de ser fiel e combativo trabalhador para mudar essa realidade" 3 . Postura que apresenta sintonia com García Espinosa (1969), quem considerava anacrônica a função de mediadores e intermediários nos documentários; por isso, percebemos que os filmes de Mirra são feitos junto aos atores e movimentos sociais, em uma criação que busca a cumplicidade no processo criativo.

Nesta perspectiva, Mirra (2017) adverte que seus documentários foram coproduções, porque ele tentou realiza-los imersos nos lugares dos fenômenos sociais abordados, em bairros ou em cooperativas e com as pessoas dos movimentos sociais, para que sirvam à sua própria memória, à sua própria organização, à sua própria consciência. No texto Huellas, que faz parte do compilatório do Movimento de Documentaristas Tomar la palavra, Mirra (2009) expressa a importância de um trabalho solidário entre os documentaristas e os atores sociais:

Eu só posso falar por mim mesmo, mas junto com vocês, eu posso falar por todos. Junto com todos. Portanto, o trabalho documentário se transforma no trabalho de todos e de cada um, atravessado por uma autoria individual e coletiva. Um tecido onde cada fio existe por si só, mas entre todos eles fazem o abrigo que nos protege do inverno. ${ }^{4}$ (p. 94).

Esta postura de Miguel Mirra dialoga com o que Jorge Sanjinés (1980) nomeou como o Segundo Método de Trabalho dos Documentaristas, que consiste em aplicar um processo de realização de dentro para fora, que se organiza com o propósito de servir e de contribuir para a luta dos movimentos sociais. A esse

2. En el registro de las imágenes, en el pensamiento, en la elaboración de los contenidos, Miguel Mirra no es un documentalista que solo registra ciertos acontecimientos, sino que trata de profundizar en esos acontecimientos, para darles contenido y que sirvan para la reflexión, para el análisis, para las vivencias y, lo que siempre digo, que estas memorias, no es para quedarse en el pasado, estas memorias ayudan a iluminar el presente y este presente es lo que da sentido a estos documentales. Original em espanhol (Tradução dos autores).

3. [...]permite que el realizador saque su obra de la realidad más objetiva, haciendo diluir todas sus aspiraciones de 'director de cine' en la necesidad de ser fiel y combativo trabajador por el cambio de esa realidade. Original em espanhol (Tradução dos autores).

4. Yo solo puedo hablar por mí, pero junto con ustedes, puedo hablar por todos. Junto con todos. Entonces el trabajo documental pasa a transformarse en el trabajo de todos y cada uno, atravesado por una autoría a la vez individual y colectiva. Un entretejido donde cada hebra existe por sí, pero entre todas hacen la manta que nos abriga del invierno. Original em espanhol (Tradução dos autores). 
respeito, Sanjinés (1980: 79) destaca que "as massas devem ser os protagonistas da história, e para o diretor é vital se unir, marchar e criar com o povo: em seu seio é onde a história acontece, e por isso é o protagonista principal". 5

Para Miguel Mirra (2017), o trabalho do documentarista "é pôr a câmera, não a serviço da denúncia, mas a serviço da organização e, assim, trabalhar em conjunto com os movimentos sociais para que eles também possam aprender a mexer e gerar sua própria imagem" 6 (Mirra, 6 de julho de 2017, comunicação pessoal).

A pauta de trabalho que se fixa nos documentários de Mirra é acompanhar as pessoas em seus conflitos ou manifestações e colocar-se a seu serviço, aceitando sugestões para um trabalho em equipe, para dar a palavra aos atores sociais, aceitando as indicações que eles fazem sobre o que filmar, o que mostrar, o que dizer (Moreira, 4 de julho de 2017, comunicação pessoal).

\section{Autogestão na política e no documentário}

Durante os dias 19 e 20 de dezembro de 2001, muitos argentinos saíram às ruas para gritar "que se vayan todos" e, naquele instante histórico da Argentina, apareceram novas formas de relações sociais (Mirra, 2009), que favoreceram o surgimento de correntes alternativas no cenário público do país e cujos esforços estavam focados principalmente na reconstrução de laços sociais mediante diferentes modelos de organização.

É necessário apontar que, a partir da crise induzida pelo sistema neoliberal na Argentina, Miguel Mirra explicitou sua identificação ideológica com os movimentos sociais em luta, através de debates nos Encontros de Cinema Documentário, organizados pelo Movimento de Documentaristas, também em escritos e manifestos, nos quais revela sua posição de defesa da autogestão, da autodefinição, da auto-organização e da independência do sistema político que, de acordo com sua percepção, havia levado o país a uma situação praticamente terminal. Em sintonia com as premissas do "movimento social de 2001", conformado pelos movimentos espontâneos de resistência popular e social que defendiam um modelo, tanto econômico como político, que estabelecia uma separação absoluta entre todas as forças políticas do momento.

$\mathrm{O}$ argumento do filme manifesta de forma explícita como a partir da autogestão os trabalhadores constroem sua própria história, que os leva a continuar

5. [...]deben ser las masas las que deben protagonizar la historia, y para el realizador es vital unirse, marchar juntos y crear con el pueblo: en su seno está ocurriendo la historia, es el protagonista principal. Original em espanhol (Tradução dos autores).

6. [...] es poner la cámara, no al servicio de la denuncia, sino al servicio de la organización y así trabajar junto con los movimientos sociales para que también ellos puedan aprender a manejar y a generar su propia imagen. Original em espanhol (Tradução dos autores). 
com o processo de inserção econômica no mercado e mediante experiências coletivas.

La cooperativa expõe a luta solidária desses trabalhadores que, apesar da crise econômica, avançam em sua organização por objetivos econômicos, sociais, culturais e meio ambientais que certificam "novos métodos de controle de produção, um novo uso do espaço e uma nova distribuição do conhecimento" 7 (Pizzi e Brunet, 2014: 41). Posição que coincide com o que expressam Mendizábal e Errrasti (2008) quando analisam que a autogestão e sua táctica autogestionária, aludem a um projeto com um profundo comprometimento econômico, social, político, cultural, ecológico, linguístico, cujos protagonistas participam diretamente nas decisões que o coletivo toma.

Em sua busca por uma cumplicidade criativa como método, tanto Miguel Mirra como o Movimento de Documentaristas, delegam na horizontalidade da autogestão sua própria práxis documental:

O Movimento de Documentáristas não tem motivações nem objetivos transcendentes para o próprio movimento. Tanto suas motivações quanto seus objetivos surgem da inter-relação entre as motivações e objetivos de seus membros em relação ao movimento social. Tampouco existem os "a priori", fora dos processos de mobilização e crescimento individual e coletivo. Nem existem imposições estéticas ou ideológicas. Apenas algumas diretrizes e princípios metodológicos. A saber: não impor as próprias ideias aos outros, colaborar com projetos e se relacionar na reciprocidade e solidariedade com os companheiros. Independência do poder político e econômico e dos aparatos burocráticos políticos, sociais ou sindicais. Marcha sempre com os explorados, os oprimidos, os discriminados. ${ }^{8}$ (p. 155)..

\section{La cooperativa}

O documentário La cooperativa relata o trabalho desenvolvido pela União Solidária de Trabalhadores, que se converteu em um dos modelos exemplares de movimentos cooperativas na Argentina. Acompanhamos, através de relatos dos seus membros, como ocorreu o processo fundacional da UST, em plena crise econômica e social, e suas diversas atuações de trabalho, sublinhado constantemente as lutas, impasses, conquistas, a organização solidária, horizontalidade e autogestão, além dos alcances obtidos tanto na gestão econô-

7. [...] nuevas modalidades de control de la producción, un nuevo uso del espacio y una nueva distribución del saber. Original em espanhol (Tradução dos autores).

8. No hay imposiciones estéticas o ideológicas. Solo algunas pautas metodológicas y de principios. A saber: no imponer las ideas propias a los demás, colaborar con los proyectos y relacionarse en la reciprocidad y la solidaridad con los compañeros. Independencia del poder político y económico y de los aparatos burocráticos políticos, sociales o gremiales. Siempre marchar junto a los explotados, los oprimidos, los discriminados. Original em espanhol (Tradução dos autores). 
mica e produtiva como no trabalho social e cultural que foi desenvolvido junto à comunidade local, em um dos setores mais humildes do sul de Bueno Aires.

Mirra construiu o filme juntamente com o setor de Comunicação da UST e se adentrou no particular microcosmo que constitui a natureza e a essência da UST. Ao explicar suas motivações, o diretor, em entrevista com a agência Télam (2016), diz que o trabalho da UST "na minha opinião, foi uma experiência muito importante, não só porque foi mantida ao longo do tempo, mas porque foi crescendo com o ensino médio, o rádio, o empreendedorismo ecológico e toda a sua atividade com a comunidade". ${ }^{9}$ Essa preocupação pode ser percebida pelo destaque que a rádio comunitária La Rebelde, tem na estrutura do filme, pontuando temas e construindo uma cumplicidade na construção da narrativa.

\section{Estrutura do filme}

Créditos iniciais Miguel Mirra-Movimiento de Documentaristas

Primeira parte de créditos. Imagens do arquivo da inauguração da escola Arbolitos.

Sequência 1. Introdução

Apresentação da história da cooperativa e segunda parte de créditos.

Chegada dos trabalhadores à empresa, começando suas rotinas de trabalho.

Os trabalhadores em ação durante a jornada diária e finalizando seu trabalho. Canção: Compañero (Farolitos).

Sequência 2. História: começo da luta em 1998

Testemunho conjunto de mulheres, começo da iniciativa, sobreposto em Wipe várias imagens de entrada de veículos na cooperativa. Mulheres na cooperativa.

Testemunhos dos homens trabalhadores.

Sequência 3. História: cooperativa estruturada

Voz em off com imagens de trabalhadores.

Testemunho de Federico. Conta onde trabalha.

Imagens dos escritórios.

Testemunho do tesoureiro da UST.

9. [...]me pareció que era una experiencia muy importante, no solo porque se sostuvo en el tiempo, sino porque fue creciendo con el bachillerato, la radio, el emprendimiento ecológico y toda su actividad con la comunidade. Original em espanhol (Tradução dos autores). 
Sequência 4. Emissora La Rebelde: As lutas

Imagens da emissora La Rebelde, com voz em off da locutora.

Programa de rádio. Entrevista com Ana, Aurelia e Alejandra Quinteros. Histórias de luta da UST, no programa, as mulheres narram a origem do bairro a relação dele com a cooperativa.

Imagens exteriores da emissora La Rebelde, com voz em off da locutora.

Sequência 5. Projetos ambientais e agroecológicos

Testemunhos e imagens do campo. História do início do projeto agroecológico da cooperativa, e seu afastamento de postulados capitalistas.

Sequência 6. Assembleia e cultura de trabalho

Assembleia da comissão administradora. Discussão, autocrítica e afirmação da organização. Debate com a participação de vários trabalhadores. Debate pós-assembleia com associados mais velhos.

Relações trabalho-cultura com a participação de vários trabalhadores.

Sequência 7. Programa de rádio projetos agroecológicos. Autogestão

Emissora La Rebelde do Centro Agroecológico da cooperativa.

Entrevistas no programa sobre o meio ambiente e a segurança alimentar.

Sequência 8. Economia solidária, ajuda à comunidade do bairro

Oficina de fundição e testemunhos de trabalhadores e diretores com alguns filhos dos empregados.

Sequência 9. Suporte a Wilde

Testemunho do padre Luis Sánchez. Imagens do arquivo.

Imagens de trabalhadores construindo o parque e as ruas do bairro San Lorenzo de Wilde.

Testemunhos das atividades esportivas e a importância do colégio.

Sequência 10. Educação popular

Imagens da rádio e programa com mulheres da escola Arbolito da UST.

Testemunhos sobre a escola da UST e a ação desta no bairro.

Sequência 11. Epílogo Depoimentos sobre as decisões políticas da cooperativa. O papel da Assembleia nas decisões coletivas.

Imagens e depoimentos de crianças brincando. 
Créditos finais

Imagens das marchas nas ruas de Buenos Aires. Canção: Oración del remanso de Farolitos.

\section{Análise geral}

A análise geral do filme La cooperativa visa tentar como a proposta de um processo criativo conjunto com os atores sociais constituiu formas narrativas próprias. La cooperativa exalta o método de organização da UST a partir de uma clara reinvindicação ideológica: promover as políticas de empreendimentos de autogestão, horizontalidade trabalhista e uma economia mais humana, no qual os processos que formam a cadeia produtiva se realizam responsável e solidaria.

O documentário está estruturado em onze sequências e cinquenta segmentos que demarcam seu trajeto narrativo, por meio de uma montagem que encadeia tópicos em torno de três eixos: A história da UST (com lutas e conquistas), suas ações e a sua forma de organização.

O começo do filme apresenta imagens de arquivo de 2008, com a construção e inauguração da escola Arbolito, o qual ouve-se o discurso proferido na época pelos diretores da UST. Este momento é tomado como um marco na história da cooperativa, configurando-se como primeiro passo social de organização trabalhista rumo à comunidade local.

Os créditos da abertura do filme se apresentam primeiro na imagem de arquivo da inauguração do colégio e depois nas imagens gerais de lugares adjacentes a UST (a costa, o campo e uma imagem aérea do bairro). O filme imediatamente sugere uma localização, num contexto vital no qual acontecem fatos históricos e geográficos, e que também insinuam a abordagem do meio ambiente como um dos temas do documentário.

Os segmentos seguintes da sequência mostram o início das primeiras atividades diárias dos trabalhadores da UST, o caminho de bicicleta até a sede da cooperativa. Aqui inicia a presença da narração da rádio La Rebelde, fazendo uma introdução da história da empresa e algumas de suas ações, funcionando como uma referencia consciente da memória da UST, constituindo uma interligação com o espaço público.

$\mathrm{Na}$ cena seguinte, os trabalhadores aparecem cuidando da conservação de uma estrada, na banda sonora, a canção Compañero da banda Farolitos, reforça a perspectiva de um trabalho pautado por um propósito comum: 


\author{
Frondoso ese horizonte es el destino \\ $Y$ aunque ande lejos allá me voy \\ Abro camino junto con vos...
}

O bloco seguinte inicia com os testemunhos de quatro trabalhadoras que relatam como foram os traçados iniciais do processo fundacional da UST: os períodos de luta, o fechamento da rodovia Buenos Aires-La Plata e também como gradualmente se formou a camaradagem entre os trabalhadores. A fala delas é mostrada por uma pequena 'janela' na tela, na qual aparecem imagens delas a caminho da sede da cooperativa e realizando trabalhos na cozinha.

Alternam-se em seguida os testemunhos de dois dos fundadores da UST, que relembram alguns dos pormenores da constituição da cooperativa, onde após quinze anos de trabalho, alcançaram um elogiável desenvolvimento econômico e social, da mão tanto de seus trabalhadores, quanto a comunidade de Wilde. E, neste contexto, as imagens que prevalecem são do restaurante comunitário, epicentro do desenvolvimento das primeiras reinvindicações dos trabalhadores e da oficina de marcenaria, onde atuavam alguns dos fundadores. Palavras como "luta", "camaradagem", "cooperativa", "familiares", "cortes" prevalecem no discurso do "inventário" histórico dos membros mais antigos.

Esta sequência reforça ao espectador as dificuldades que enfrentaram os trabalhadores: por um lado, a instabilidade da própria empresa, por outro, a situação política e econômica da Argentina que anunciava um futuro sombrio para os trabalhadores desempregados e para suas famílias.

O bloco seguinte começa com imagens aéreas da sede da empresa e, num tom observativo, mostra o funcionamento das oficinas do conselho da administração, na qual vemos Mario Barrios.

Na sequência seguinte, novamente a rádio La Rebelde aparece com destaque, assumindo agora outro protagonismo. Ainda sobre as imagens anteriores, escuta-se um trecho de uma transmissão. Aos poucos surge a imagem da torre de transmissão, que se funde com equipamentos de transmissão e finalmente a câmera se introduz no estúdio da emissora. Nele vemos dois apresentadores realizando o programa Los especiales de la Unión Solidaria de Trabajadores no qual entrevistam as trabalhadoras Ana, Aurelia e Alejandra, que retomam o tema das lutas e referenciam também à paulatina relação e compromisso da UST com as famílias do bairro San Lorenzo, especialmente com mulheres, crianças e jovens.

Aqui já se evidencia, de maneira mais visível, uma estratégia persuasiva do filme. A UST já não é apenas empresa, agora a UST, os trabalhadores, suas famílias e a comunidade adjacente de vizinhos aparecem juntos, envolvidos com o movimento solidário. O uso do "nós" nas falas, é uma estratégia retórica para 
que o espectador consiga distinguir que o "compromisso" dos trabalhadores se traduz numa responsabilidade social, e preocupação com o meio ambiente. $\mathrm{Na}$ passagem para a outra cena, o som da chamada da rádio sobre imagens da torre e aéreas da região rumo a uma área de campo, simulam a propagação das suas ondas com as notícias da UST e um trajeto, anunciando o próximo tema.

A sequência 5 introduz uma nova categoria de ação de UST: os projetos ambientais e agroecológicos, autogestionários e autossustentáveis. Nesse trecho, o filme apresenta os projetos de sustentabilidade com o meio ambiente da cooperativa, que ajudam a manter viva a biodiversidade, em meio de uma aprendizagem permanente com a natureza e que marcam uma grande diferença com os modos de produção de uma empresa capitalista tradicional. A intenção da UST é melhorar a qualidade de vida e criar novos postos de trabalho, sempre tendo como eixo a comunidade do bairro. Novamente a estratégia é mostrar os depoimentos em pequenas janelas sobre imagens do cotidiano da fazenda experimental.

Durante a sequência 6 acompanhamos uma assembleia entre os trabalhadores da cooperativa. Inicia com a assembleia da comissão administradora, na qual os personagens se imbricam em discussões que visam a autocrítica do trabalho realizado e, ao mesmo tempo, a uma reafirmação da própria organização: um debate com a participação de vários trabalhadores, o que denotaria tanto o status democrático como a horizontalidade da UST. Na sequencia há duas reuniões com alguns dos associados mais antigos da cooperativa, ambas funcionam como falas explicativas sobre a importância daquelas assembleias, e são, pela sua artificialidade, direcionadas ao espectador para reforçar o papel da assembleia naquela "cultura do trabalho".

A mensagem é novamente clara: a UST é uma entidade democrática, na qual todos os trabalhadores são iguais e todos, sem exceção, têm os mesmos direitos e deveres para cumprir. Esta sequência aponta a autocritica como uma qualidade que possuem os cooperativistas da UST, reconhecer os acertos, mas também os desacertos sob o lema dos próprios trabalhadores: ninguém é perfeito, mas admitir os erros ajuda o crescimento pessoal e coletivo.

Do mesmo modo, a montagem que Mirra esboça na sequência tem a função de manter uma continuidade lógica entre os pontos de vista dos personagens que participam ativamente desse debate. Nessa parte do documentário se estabelece outro tipo de ritmo da ação documentada pois, além de desenvolver em maior profundidade as reações íntimas dos atores sociais, também permite, mediante a montagem, utilizar primeiros planos, planos detalhes ou planos complementários, como sutil referência do que os personagens estão vendo ou pensando. 
Até este instante, o documentário expôs alguns dos eventos históricos mais importantes que possibilitaram o surgimento, constituição e consolidação da UST; assim mesmo, se apreciaram também aqueles componentes de caráter ideológico e político que determinam o trajeto de cada um dos membros da cooperativa, permitindo continuar seu trabalho.

Nas sequências seguintes, o filme implica-se na exposição da UST em seu papel de organização "provocadora" de projetos comunitários e produtivos internos e externos, que significaram a geração de fontes de emprego, alternativas e inovadoras.

Primeiramente, na sequência 7, com o mesmo recurso de uso da filmagem de um programa radiofônico como elemento narrativo, os repórteres de $L a$ Rebelde entrevistam Hugo Villa e Daniel Bossio, respectivamente advogado e engenheiro agrônomo da cooperativa no espaço do Centro Agroecológico. Num esquema similar ao utilizado por Mirra na sequência 4, temos agora a promoção de assuntos ambientais e agroecológicos, com hortas orgânicas e um viveiro de plantas nativas, que envolve os trabalhadores mais jovens em processos de capacitação. A premissa é: meio ambiente, segurança alimentar e uma UST amiga do meio ambiente.

Em seguida, a narração da sequência 8 converge no 'legado da cooperativa', ou seja, temos uma UST que vai se estendendo de geração em geração: avós, pais, filhos e netos; aqui o filme enfatiza o patrimônio imaterial da UST. Mirra agrupa os filhos de trabalhadores fundadores para reforçar esta perspectiva e a mensagem: existe uma transmissão geracional de valores da UST.

Porém, devido a um dispositivo de montagem recorrente nos documentários de Mirra, que decide "enquadrar" as entrevistas em 'janelas', a imagem perde impacto e se distancia do espectador, sobressaindo-se mais cenas de trabalho, desta vez com tratores. O que gera a percepção que os jovens não são participativos, estão visualmente na cena mais não destacam, não opinam, são passivos. Mas prevalece o discurso de esperança na continuidade daquela experiência de trabalho com os mais jovens pouco a pouco participando das atividades da Cooperativa.

Na passagem para a outra sequencia, Mirra incorpora uma imagem de arquivo com uma fala do padre Luis Sánchez, apontado por trabalhadores mais antigos, como a inspiração ideológica do grupo que formou a Cooperativa. Nela, Sánchez fala da experiência da "cooperativa trabalhista" como alternativa ao modelo capitalista de trabalho.

A partir das sequências 9 e 10 o diretor reforça a informação apresentada nas sequencias anteriores: ressaltar o apoio que a UST fornece à comunidade de Wilde, mostrar ao espectador uma cooperativa humana, responsável e subs- 
tancialmente diferente das empresas de modelo capitalista "tradicional", mas não isolada do mundo. E o foco são as atividades na escola Arbolitos, inicialmente explicadas pela 'voz' da narradora da rádio e em seguida pelos próprios professores, trabalhadores, alunos da escola e seus pais, moradores da região.

A sequência 10 novamente o recurso da gravação na emissora La Rebelde; no segmento, os jornalistas entrevistam um casal de docentes: Nora e Graciela. Elas reiteram os pontos positivos da escola Arbolitos como um eixo importante do vínculo educativo da UST com os jovens e adultos da comunidade.

A sequência final se inicia com Diego Ledesma, presidente da UST que, numa espécie de conversa com alguns trabalhadores da UST em torno de uma mesa, sublinha as decisões políticas que se tomam na cooperativa. Destaca a importância de um modelo assembleário e coletivo, e fundamentalmente tanto a vontade de lutar da empresa como o vínculo constante desta com os vizinhos do bairro. Não obstante, tal como acontece com os jovens na sequência 8 , os trabalhadores se mostram distantes, inativos e sem reação ao discurso do diretivo, não há replica ou complementariedade das palavras de Ledesma. A composição do enquadramento sugere, a priori, a abertura para um momento de debate, mas este não se efetua. Assim, o que Ledesma quis expor estranhamente não se aproveita, em parte pela inércia dos trabalhadores, "excluídos" do discurso e com a falta de uma explicação visual no encontro dialógico.

O filme termina com varias imagens de crianças e de jovens compartilhando e brincando nos espaços recreativos da UST, que mostra um ambiente descontraído, como um epílogo que metaforicamente pretende fortalecer a mensagem de outro mundo possível, com uma crença no futuro.

Para os créditos finais se observam uma série de imagens das marchas da UST, reforçadas pela música Oración del remanso da banda Farolitos. Os créditos terminam com uma dedicatória aos colegas da UST.

\section{Considerações finais}

A estética que imprime Miguel Mirra em La cooperativa, mantém suas marcas gerais de austeridade e minimalismo, o que dá primazia ao que dizem os atores sociais (os excluídos). Desse modo, tal como sucede em outros documentários de Miguel Mirra como Tierra de mujeres: De Winifreda a Famatina (2011), Darío Santillán, la dignidad rebelde (2012) ou Autogestión (2017), para mencionar alguns de seus mais recentes filmes, os meios que utiliza o cineasta em La cooperativa, constituem uma sucessão de elementos tradicionais de documentários de observação, participativos (interativos) e expositivos. A novidade que apresenta o documentário é o uso de várias câmeras para recolher 
os testemunhos nos debates, isto possibilita uma melhor cobertura da dinâmica da ação.

Por outro lado, é perceptível que Mirra, enquanto observa de maneira "aparentemente espontânea" o que realizam os homens e as mulheres da UST diante da câmera. Mirra tenta mostrar o cotidiano dos trabalhadores da UST, temporal e espacialmente, como se experimenta a "cotidianidade" na empresa (a chegada do trabalhador de bicicleta ou as reuniões e atividades dos trabalhadores nas oficinas). Possibilitando que o espectador assuma uma posição mais crítica a estes processos; um procedimento similar ao que encontramos em documentários de Frederick Wiseman.

$\mathrm{O}$ diretor também aproveita as entrevistas na emissora La Rebelde para validá-las ante o espectador e criando uma cumplicidade com aquela forma de difusão das ideias da UST, constituindo a rádio de uma importância diferenciada na estrutura narrativa do documentário.

De outra parte, o discurso que Mirra constrói no documentário também recorre a elementos como as entrevistas testemunhais ou entrevistas conversacionais. O emprego da música se manifesta como um recurso que está fortemente envolvido com o andamento do eixo dramático do filme, e reforça passagens narrativas do mesmo; por exemplo, a primeira sequência, quando se exibe a amizade entre os trabalhadores, a canção Compañeros torna mais forte a mensagem de solidariedade, cooperação e amizade; do mesmo modo, Oración del remanso, serve como elemento introdutório para a sequência da qual se fala do forte vínculo entre a UST e seu entorno imediato, mas também se utiliza para os créditos finais.

Destaca-se também o uso da voz em off na sequência inicial do documentário e o trecho sobre as experiências comunitárias, cujo texto se apresenta como informativo, e, no estilo, dialoga com a narração radiofônica.

Em La cooperativa, Mirra vai se adentrando nas convicções daqueles que fazem parte da UST, para que o espectador as observe e perceba, para exibir a principal tese do documentário: a questão da sobrevivência de uma organização cujo apoio são os cerca de 140 funcionários autônomos, sem chefes e que fundamenta suas ações em princípios econômicos e ideológicos, democráticos e não capitalistas.

Com um cunho que por vezes pode soar como panfletário, o diretor expõe as qualidades, desafios e estratégias desse tipo de organização e ao mesmo tempo apresenta uma crítica aos modelos econômicos que historicamente foram desfavoráveis para a maioria da população argentina. 


\section{Referências bibliográficas}

Álvarez, C. (2002). Postulados del tercer cine. In P. Paranaguá (ed.), Cine documental en América Latina (pp. 466-467). Madrid: Cátedra Signo e imagen.

Birri, F. (1964). La escuela documental de Santa Fe. Santa Fe: Editorial Documento del Instituto de Cinematografía de la UNL.

Bordwell, D. \& Thompson, K. (2010). Film art. An introduction. $9^{a}$ edición. New York: McGraw-Hill.

García Espinosa, J. (1969). Por un cine imperfecto. Caracas: Rocinante.

Mendizábal, A., Errasti, A. (2008). Premisas teóricas de la autogestión. Jornadas de Economía Crítica, ECOCRI. Jornadas llevadas a cabo em Bilbao, España. Marzo. Disponível em: http://webs.ucm.es/info/ec/ecocri/eus/M endizabal_y_Errasti.pdf.

Mirra, M. (2009). Ideas fundacionales del movimiento. In F. Álvarez, et al., Tomar la palabra. Pensamiento, acción y palabra del movimiento de documentalistas (pp. 94-155). Buenos Aires: Editorial de la Universidad Nacional del Comahue.

Nichols, B. (1997). La representación de la realidad. Cuestiones y conceptos sobre el documental. [Representing Reality: Issues and Concepts in Documentary] $1^{\text {a }}$ ed. Barcelona: Ediciones Paidós.

Pizzi, A. \& Brunet, I. (2014). Autogestión obrera y movilización social. El caso de las empresas recuperadas argentinas en la Ciudad de Buenos Aires y Provincia de Buenos Aires. Latin American Research Review, 49(1), 39-61. Pittsburgh. Disponível em: http://lasa-4.univ.pitt.edu/LARR/prot/ fulltext/Vol49no1/49-1_39-61_pizzi-icart.pdf.

Sánchez Noriega, J. (2002). Historia del cine, teoría y géneros cinematográficos, fotografía y televisión. $1^{\mathrm{a}}$ ed. Madrid: Alianza Editorial.

Sanjinés, J. (1980). Teoría y práctica de un cine junto al Pueblo. $1^{\mathrm{a}}$ ed. México: Siglo Veintiuno Editores.

\section{Filmografia}

Autogestión (2017), de Miguel Mirra.

Darío Santillán, la dignidad rebelde (2012), de Miguel Mirra.

La cooperativa (2016), de Miguel Mirra.

Tierra de mujeres: De Winifreda a Famatina (2011), de Miguel Mirra. 